\title{
From blended to e-learning: Evaluating our teaching strategies
}

De l'enseignement hybride à l'enseignement à distance : l'évaluation de nos stratégies pédagogiques

\section{Clive Hamilton and Lindsey Paek}

\section{OpenEdition}

\section{Journals}

Electronic version

URL: http://journals.openedition.org/asp/6611

DOI: 10.4000/asp.6611

ISSN: 2108-6354

\section{Publisher}

Groupe d'étude et de recherche en anglais de spécialité

\section{Printed version}

Date of publication: 1 November 2020

Number of pages: 47-64

ISSN: 1246-8185

\section{Electronic reference}

Clive Hamilton and Lindsey Paek, "From blended to e-learning: Evaluating our teaching strategies", ASp [Online], 78 | 2020, Online since 01 November 2020, connection on 08 March 2021. URL: http:// journals.openedition.org/asp/6611 ; DOl: https://doi.org/10.4000/asp.6611

This text was automatically generated on 8 March 2021.

Tous droits réservés 


\title{
From blended to e-learning: Evaluating our teaching strategies
}

\author{
De l'enseignement hybride à l'enseignement à distance : l'évaluation de nos \\ stratégies pédagogiques
}

Clive Hamilton and Lindsey Paek

\section{Foreword}

1 This report describes the transformation of a traditionally blended-learning course into a full elearning module during the national lockdown of March 2020 and reflects on how teaching strategies and the overall structure of the course changed as a result. The course in question is a module which prepares individuals and business professionals for the Test of English for International Communication (TOEIC) certification and is part of the wider Diplôme Universitaire Langue Anglaise Spécialisée et Certification (DULASC) programme offered at the Université de Paris. It is worth noting that the students are paying customers. The aim of this course is to improve participants' professional English language proficiency and to help them develop strategies to avoid common pitfalls of the TOEIC test. The authors adopted a qualitative research approach involving the collection and analysis of post-course questionnaire data to gain insights into the students' perceptions of the online course. Responses were gathered from 21 of the 24 students participating in the course.

2 Blended learning is the integrated combination of two learning modalities: traditional face-toface classroom instruction and on-line delivery (Garrison \& Vaughan 2008, Narcy-Combes et al. 2019, Nicolson, Murphy \& Southgate 2011, Nissen 2014). It takes advantage of both modalities in the sense that it provides learners with the flexibility of online learning (the ability to access the course from anywhere at any time and to work at their own pace), while still maintaining a strong human presence through the classroom experience (Arispe \& Blake 2012). Blended learning was first introduced into the higher education setting in the 1990's (Peraya, Charlier \& Deschryver 2014), but has witnessed considerable growth in France over the last 15 or so years (Nissen 2014) in line with the widespread adoption of technology, the internet and open learning platforms in the university context. The blend of the course described in this report is quite a 
simple one. The approach prior to lockdown combined weekly face-to-face seminars with supplementary follow-up material provided online asynchronously via the Moodle platform. As such, the online component was seen as complementary to the main delivery mode which was face-to-face. However, the national lockdown forced the university to switch to a completely online solution.

3 The authors highlight the challenges faced by students as a result of this switch, in particular due to the distance. As Lamy and Hempel (2007) note, socially and psychologically, the geographical distance between participants has an impact. Research by Shield (2000) showed the greater "aloneness factor" and anonymity that can characterise online communication. This may help explain the high drop-out rate of the online course (more than 50\% of the initial 50 participants), while those that remained asked for more personal interaction. Responses to the questionnaire also indicate this preference for human interaction. Learner self-regulation and autonomy are other factors explored by the authors through analysis of the learners' experience and feedback.

4 An underlying theme of the report is the tensions between the TOEIC instruction perspective, which is focused on helping students learn techniques to optimise their score rather than improving their overall language proficiency, and traditional English language and ESP programmes and certifications in France which adopt a more holistic pedagogical approach aimed at fostering general proficiency. It should be noted that other modules of the DULASC programme adopt this latter perspective. The psychometric philosophy behind the ETS TOEIC assessment programme brings with it limitations. Huver (2012) points to the narrow scope of the test, as well as the increasing standardisation of such language assessment practices. Tests such as BEC, DIALANG, IELTS, and TOEFL are in the same vein. The author encourages a greater diversification of assessment methods and a learner-centred approach inclusive of intercultural and socio-cultural dimensions. One such certification is the Certificat de Compétences en Langues de l'Enseignement Supérieur (CLES). Aligned with the Common European Framework of Reference for Languages (CEFR) competence levels, the CLES assesses students' receptive, productive and interactive communication skills within the framework of a realistic scenario. The associated tasks are anchored in social themes, which allow for the transferability of skills to the professional world. However, the marketability of standardised tests like TOEIC, cannot be underestimated and helps explain its wide acceptance in the business community and beyond. (Julie McAllister, Université de Nantes)

\section{Introduction}

5 Courses in English for specific purposes (ESP) are often compartmentalized and broken down into distinct teaching disciplines: for instance, English for computing. These distinct teaching niches are then taught to students enrolled in that extended domain or field. However, one may wonder whether it is possible to offer several distinct ESP courses to the same audience and, if so, to what end. This is the delicate challenge taken by the Diplôme Universitaire Langue Anglaise Spécialisée et Certification (DULASC) programme offered at Université de Paris.

6 ESP courses, like all academic disciplines, are not immutable objects, and as part of an ongoing bid to remodel the DULASC diploma, we were asked to teach the Test of English for International Communication (TOEIC) preparation course component during the academic year 2019-2020. Following the national lockdown that was imposed in March 2020 to fight the coronavirus pandemic, we were then required to 
further transform a traditionally blended-learning course into an operational elearning module, without the customary available IT and media devices and support. The three main objectives of the course, as might be expected, remained unchanged. Firstly, training students in all four areas of the language, including listening and reading-which are tested using the TOEIC certificate-and speaking and writing, for a more holistic approach; secondly, raising awareness of specialised language use and their limits in specific discourse settings; thirdly, helping students develop effective strategies to avoid the common pitfalls of the TOEIC test.

7 We now wish to reflect, compare and contrast different methods of giving instructions and evaluating students that were put into place during the online course. Given the novelty of the experience, our students' perspective was also required for a holistic assessment of the course delivery. As a result, post-course questionnaires were distributed to students for feedback.

This report presents the overall organization and structure of the module and discusses the aspects affected by the lockdown situation. Areas for future improvements are also addressed.

\section{Context}

The DULASC diploma is a one-semester only intensive programme that caters for individuals as well as enterprises and aims to further improve all participants' professional English language proficiency. Some modules are conducted from January to March, while the others run from April to June. Student admission is conditioned by an online in-house English language placement test, with B1 being the minimum requirement. Successful applicants must also have at least a bachelor's degree and are then divided into two different groups depending on their academic and professional profile: i.e. natural sciences and human sciences. In this year's programme, each group was limited to twenty-five students and had its own instructor. By the time the national lockdown measures were out into place, only twelve students remained in each group, who continued to attend classes and completed weekly coursework. These students had already completed most of the three ESP modules adapted to their specific group profiles in the DULASC programme.

10 The TOEIC Listening and Reading test is proposed to all participants at the end of the DULASC teaching programme, and the corresponding preparation module was, as a result, one of the last two courses that began during the national lockdown. This module uses the previous ESP modules to gain an important foothold and traditionally adopts a blended learning approach; this approach was replaced by a temporary elearning protocol. The lockdown measures put into place presented several challenges for the planning and delivery of the course, three of which are succinctly highlighted. Firstly, course materials, such as TOEIC textbooks, sample tests, as well as grammar and vocabulary books relevant to the TOEIC training, had been left at the university. They consequently remained inaccessible for the instructors who had to seek other resources to prepare the module. Secondly, while the learning platform Moodle provided a valuable online space where the course materials and resources could be shared, it presented restrictions in providing a timed environment, which is an important aspect of the TOEIC preparation. Timing being a crucial element of training for the TOEIC test, students could only be encouraged during the course to respect the 
time limit and time themselves on their own. Thirdly, as the coronavirus crisis has affected the full delivery of the DULASC programme, the date of the actual TOEIC test remains undecided. Therefore, students could only be strongly encouraged to continue training on their own to ensure that they remain prepared for the test.

11 Unlike other modules in the DULASC or other university programmes which would have started before the lockdown, and where there may have been an established student-teacher dynamic, the TOEIC module did not benefit from such a relationship. The module started during the lockdown and students had not previously met their instructors. It was therefore important to ensure that the course be easily accessible to every student, and that each class be designed in a way that clearly communicates weekly goals and instructions to keep the students engaged and motivated.

\section{Course objective and design}

One of the guiding principles of the DULASC diploma is fostering proficiency development in specialised language use: i.e. in both written and spoken modes, particularly in workplace and academic discourse. All the constituent modules, except the TOEIC preparation course, cater for specific discourse communities (see Swales (2016) for discussion), and consequently the corresponding content, tools and language techniques used are adopted from the target community. The DULASC programme has made the choice of the TOEIC listening and reading test, as opposed to its speaking and writing equivalent. However, the preparation module is not limited to any one speech or discourse community, but rather overlaps or aggregates various professional language registers and contexts. As a result, as mentioned earlier, the preparation module is scheduled after the completion of the first three ESP modules-which are generally taught from January to March-in order to facilitate the interdisciplinary professional language approach put in place, where the previously acquired ESP knowledge and awareness are used as building blocks.

Another important differentiating principle between the TOEIC course and other DULASC modules lies in the choice of content and assessment. ESP content is selected based on attested language usage: via previously acquired and examined corpus data where syntactic patterns, terminology and phraseology are reinjected into course content and their corresponding evaluations. Given the TOEIC certification objective, the course content is not predominately guided by local institutional considerations, but rather the onus is on course designers to adapt the course material to the prerogatives of the Education Testing Services (ETS). ${ }^{1}$ Choice of content-whether it concerns grammar points, specialised terminology, thematic discourse settings and their traditional conventions and sequence of events-cannot be freely decided by instructors. The specificity of the TOEIC module is therefore twofold: on the one hand, preparing the students for the external assessment and, on the other, heightening their awareness and use of professional discourse, while exploring its recurrent conflating or overlapping nature.

14 The leeway afforded to DULASC TOEIC instructors resides not in the overall course objective nor content but rather its design, where pedagogical transmission strategies play a vital role. 


\subsection{Language proficiency: beyond contextual language use} "approved ETS" material is a rite of passage for all TOEIC instructors and course content creators. Notwithstanding, as linguists and language teachers, the rhetoric of traditional course material seems to converge primarily towards optimising one's score. This key marketing strategy is often visible at first glance. As a direct result of this strategy, our students/TOEIC candidates are particularly keen on learning tricks of the trade, which they believe would help to optimise their score and overall chance of securing future job or university placements. Alternatively, improving overall proficiency, which is the cornerstone of many English language programmes in France (especially general proficiency and increasing the Common European Framework of Reference for Languages (CEFR) competence levels)-notably in LANSAD ${ }^{2}$ departments -appears to be sidelined, as it is not explicitly mentioned in published "approved" or "official" materials available. The absence of this tried-and-tested pedagogical objective, in both language research and teaching circles, warrants further questions and pedagogical implications that will not be examined in this report.

The ETS TOEIC assessment programme and their corresponding grammar exercises or specialised terminology can be considered random snippets of contextual language use. Nonetheless, a wider scope of interconnectedness between syntactic structures and their propositional content is never explored, neither are the higher-ranking governing language structures. For instance, does being able to construct and/or identify a passive verb group automatically confer the ability to use it appropriately? Can it be used or is it frequent in all registers? Does understanding the information in executive minutes confer the ability to write one? This apparent counter-intuitive or narrow-niched ESP approach opposes that of ESP practitioners aiming at holistic language proficiency development (see Huhta et al. 2013). Situating ourselves in the latter group forces us to identify and address shortcomings of the ETS assessment programme in order to widen the scope and its resulting pedagogical perspective before conducting our TOEIC preparation course.

17 In short, ETS TOEIC assessment hinges towards highly specific contextual language usage, which is still commonly excluded from LANSAD course content, in spite of the growing ESP movements in and around France. However, as ESP practitioners, it appears vital that this specific usage be appraised along with the language comprehension and awareness needed to foster general proficiency. Consequently, the subsequent transferability and adaptability of these acquired language skills to different discourse communities constitute the missing piece that has been added to the course objective of the TOEIC preparation module.

\subsection{Revamping transmission strategies}

Outlining objectives is often the first step in curriculum design. In our case, linguistic objectives preceded their pedagogical strategic counterparts. In addition to the external culminating summative assessment scheduled at the end of the DULASC programme, one of the guiding strategic objectives was to align and balance the following three important facets: i.e. satisfying the needs and expectations of (i) ETS skills requirements; (ii) the DULASC's ESP pedagogical perspective; and (iii) the paying 
customer, the student. It is noteworthy that the latter selected and paid for a costly service, in comparison to undergraduate or postgraduate French students enrolled in national degree programmes - where a similar client-power dynamic is relatively nonexistent. Our students expect the TOEIC module to be different from previously attended general language courses in past university degree programmes, as well as from other DULASC modules that took place during the months of January to March.

Each facet mentioned above warrants a particular learning and teaching strategy in its own right, which in turn has specific implications. Let us examine them briefly. Implication A: the ETS knowledge requirements, which differ from knowledge comprehension, can be equated with rote learning. Implication B: the ESP perspective adopted, which aims at raising specific language awareness, requires us to compare and contrast discourse communities, whether in linguistic or metalinguistic terms. Implication C: our TOEIC test candidates consider the test a strategic hurdle, one that we must help them to overcome. As a result, their focus lies in identifying problemsolving strategies, regular pitfalls or tricks of the trade. Our teaching must therefore encompass all three implications. However, in an ongoing attempt to revamp the course, two different teaching strategies were up for appraisal and tested in pairs: they concern strategies A \& B and A \& C respectively. The combination B \& C is excluded given that A provides the primary linguistic content material.

The compulsory transformation from blended to e-learning did not impact the ongoing reflection and the two teaching strategies were tested as indicated in Table 1.

Table 1: Group distribution

\begin{tabular}{|l|l|}
\hline Science group & Humanities \\
\hline Implications A \& B & Implications A \& C \\
\hline
\end{tabular}

\subsection{Course transformation at the eleventh hour}

The objectives and design of the TOEIC preparation module precede the national lockdown and subsequently remain unchanged. The course management and delivery, however, were transformed in order to adapt to the situation. The course's traditional blended-learning approach, which can be summarised as a weekly face-to-face seminar with supplementary follow-up material provided online, morphed into an entirely elearning module. As mentioned earlier, the sudden change in situation resulted in restricted access to primary material: i.e. language laboratory, worksheets, audio recordings and corresponding tape scripts, along with other acquired official and or approved ETS documents ordinarily stored at the university. Temporary replacement material had to be sourced online and innovative and experimental choices were made. Table 2 offers a succinct overview of these choices, in light of the ongoing revamping strategies under appraisal.

Table 2: Comparison of teaching strategies

\begin{tabular}{|l|l|l|}
\hline & Humanities group & Science group \\
\hline
\end{tabular}




\begin{tabular}{|c|c|c|}
\hline $\begin{array}{l}\text { Teaching } \\
\text { Strategies }\end{array}$ & $\begin{array}{l}\text { Problem-solving oriented } \\
\text {-Identify problem areas in TOEIC test, by } \\
\text { section } \\
\text {-Weekly intensive practice, by section } \\
\text {-Teaching via videoconference calls, timed- } \\
\text { quizzes via Kahoot! and traditional powerpoint } \\
\text { presentation, interaction encouraged } \\
\text {-Supplementary material provided }\end{array}$ & $\begin{array}{l}\text { Knowledge-based oriented } \\
\text {-Diagnostic TOEIC assessment } \\
\text {-Specialised grammar \& } \\
\text { vocabulary provided } \\
\text {-Weekly comprehensive } \\
\text { assessment and drills } \\
\text {-Teaching via uploaded reading } \\
\text { material } \\
\text {-Q\&A via audio-only conference } \\
\text { calls }\end{array}$ \\
\hline Audio/video & $\begin{array}{l}\text {-Pre-recorded voiceover for some listening } \\
\text { exercises } \\
\text {-Live videoconference calls ( } 1 \mathrm{hr} \text { weekly) }\end{array}$ & $\begin{array}{l}\text {-Pre-recorded audio detailing } \\
\text { course outline \& instructions } \\
\text {-Live conference calls ( } 30 \text { minutes } \\
\text { weekly) }\end{array}$ \\
\hline Evaluation & -Weekly evaluation, with answer key provided & $\begin{array}{l}\text {-Weekly evaluation, some graded } \\
\text { by the instructor, answer key } \\
\text { provided for others }\end{array}$ \\
\hline $\begin{array}{l}\text { (additional) } \\
\text { Interaction }\end{array}$ & $\begin{array}{l}\text {-Emails, videoconference calls, timed-quizzes } \\
\text { on Kahoot! }\end{array}$ & $\begin{array}{l}\text {-Q\&A forum provided, managed } \\
\text { by the instructor after conference } \\
\text { calls }\end{array}$ \\
\hline $\begin{array}{l}\text { Platforms, } \\
\text { tools }\end{array}$ & $\begin{array}{l}\text {-Jitsi for videoconference calls } \\
\text {-Kahoot! for warm-up/review } \\
\text {-Moodle for uploaded material }\end{array}$ & $\begin{array}{l}\text {-Renater for audio only } \\
\text { conference calls } \\
\text {-Moodle for uploaded material }\end{array}$ \\
\hline
\end{tabular}

Let us now briefly examine the overall structure of the course delivered online. The ongoing reflection about modernising the TOEIC module led us to identify and arrange the most preeminent teaching strategies that traditionally govern the course into two groups: i.e. problem-solving vs knowledge-based teaching approach (see Jaleniauskiene 2016 and Hegarty 2000 respectively, for discussion). Each approach was then assigned to one of the two DULASC groups according to the preferences of the instructors. In addition, in order to instil a routine and encourage rapid comprehension, the layout of the weekly sessions was identical throughout the duration of the online course, but remained specific to each group.

23 For the humanities group, each week was dedicated to examining specific parts/ sections of the ETS TOEIC test and communicating test-taking strategies that prove pertinent to each. Subsequently, students were provided with sample test questions for the parts that were reviewed in order to practice on their own. Answers to the questions were available on Moodle for the students to self-correct their attempts. While none of the sample tests were collected, during the video conference each week, the students were required to work on some sample questions from the previous week in order to check their level of understanding of the acquired strategies. format. Frequent grammatical pitfalls, key grammar points and terminology were also 
provided in each session. The onus was on the student to identify personal test-taking strategies. The time-consuming nature of the TOEIC test structure obliged students to choose between which activity they completed during the online class schedule and which they did later: i.e. between the mock drills or the content lessons. This option was given to ensure that those with internet connection problems were not penalised, as long as the other activity was done within a 24-hour window. This particular setting paved the way for the instructor to become a platform facilitator rather than assuming the traditional role of imparting knowledge, during the online course.

Additionally, in terms of delivery and lesson plan, the humanities group was divided into two halves. During the first hour, the students would engage in a videoconference meeting with the instructor and during the second hour they would be asked to train themselves, using a variety of exercises that were made available on Moodle. This simple and clear organisation remained consistent throughout the course in order to ensure that it was understood and followed by everyone. The science group on the other hand was initially intended as an autonomous class: i.e. with automated sections, pre-recorded audio outline and instructions at the beginning of each week's session. Additional recordings were to be added at each new section, per lesson. This format was changed to incorporate weekly 30-minutes conference calls, at the request of students who voiced concerns about interactivity. A Wiki Q\&A forum was also created for the science group, in order to regroup all course-related questions that students posed during or after the online module.

\section{Navigating between student feedback}

Obtaining and combining a teacher and student perspective on a shared learning environment is a crucial part of holistic classroom evaluation. Frequently re-examining teaching approaches is an important part of self-evaluation and improvement, provided that this step targets both content and teaching strategy assessment. Alternatively, a student's outlook can help provide necessary feedback on course format and reception. Together, the teacher and student facets allow us to improve simultaneously both the methods of delivery and the methods of reception of content, which translate into a renewed and heightened learning experience for our students. Section 4 explores teacher feedback.

\subsection{Student learning environment}

The post-course questionnaire was designed in such a way as to elicit three different types of information from our students, viz. concerning their learning environment during the online module, their opinion on the course content and structure as well as its format. Twelve students participated in the humanities group as well as the science group for a total of 24 students, 21 replied to the online questionnaire. While the majority in each group holds that access to the online course was not a critical issue, it is worth noting that a sizable minority of participants indicated that they lacked adequate technological equipment and devices. More precisely, 23\% did not have unlimited access to a personal computer; $33 \%$ had internet problems and experienced poor video or audio quality in conference sessions and a further $42 \%$ did not always have a calm environment in which to do their coursework. 
se constraints are important and should be taken into consideration when modifying the TOEIC course in the future. One may even assume that these constraints are transposable to other online modules. In hindsight, transposing the duration of a traditional face-to-face seminar to an online module may be a source of conflict for modules that are not complete lecture sessions but rather involve other types of activities during the scheduled online conference. It is therefore important to provide a wider slot for all additional online activities in order to ensure that those with low bandwidth are not penalised: notably, when there are supplementary material to be downloaded (audio, video or other voluminous files) or when the submission of assignments is required at the end of an online session. The additional slot may also prove beneficial to the $42 \%$ who do always have a calm and quiet work environment during the strict online timetable, provided that it is used to select the most convenient work schedule for them.

Regarding previous online experience, thirteen (i.e. 62\%) out of twenty-one participants indicated that they had previous experience with Moodle or another similar online platform. While this figure could be linked to the fact that previously attended modules in the DULASC programme consist of blended learning, involving Moodle, it is also possible that this or another platform was encountered during their previous university training programmes. As a reminder, all students have completed an undergraduate $(29 \%)$ or a postgraduate degree (71\%). However, as all the participants in the TOEIC preparation course had successfully completed the previous modules, the eight participants who responded that they lacked previous experience with Moodle may have misunderstood the question or may have failed to consult or keep abreast with the online part of the previous DULASC modules. Moreover, online classes appear to have been a new experience for most of the participants: thirteen (62\%) out of twenty-one responded that the TOEIC module was their first experience taking a complete e-learning course. These responses hint that, although many students are becoming accustomed to blended and distance learning, the userfriendliness of online courses should not be overlooked but rather extra attention should be paid in making them easily accessible and explorable for all.

\subsection{Student perspective on course format and content}

Overall, the survey results indicate a relatively high level of student satisfaction in course content (cf. Figure 1), structure, and organization. When asked about the adequacy of certain items (see Appendix, question 8), students expressed a preference for the combination of video and/or audio conference with reading material, as opposed to audio recording and reading material alone (cf. Figure 2). This preference suggests a certain apprehension when online modules differ from traditional face-toclasses and, as a result, a certain approval when traditional classroom settings are replicated. 
Figure 1: Overall evaluation of course content

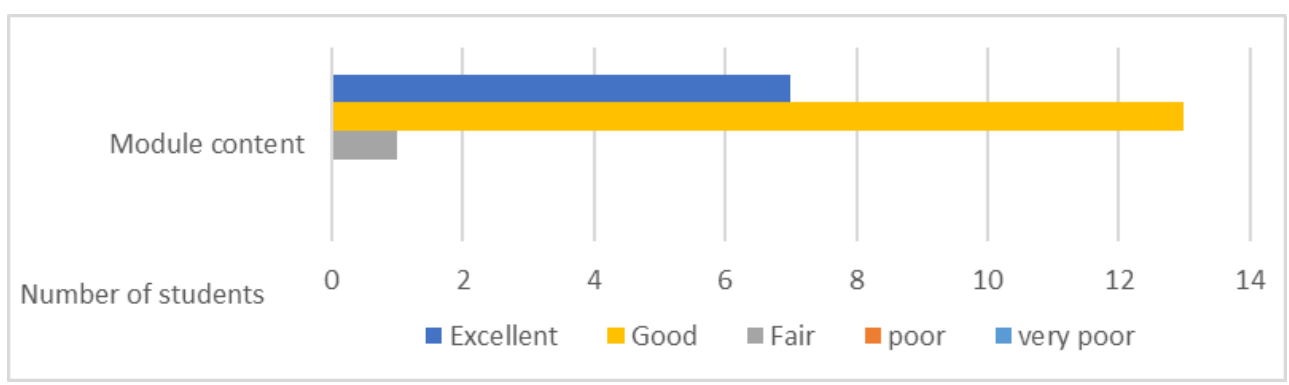

31 It should be noted that the first three items in Figure 2 are accompanied by reading material: i.e. audio-only recording (with reading material); audio-only conference sessions (with reading material); and videoconference session (with reading material). The fourth item refers to the adequacy of the reading material provided by itself.

Figure 2: Scale of sufficiency of specific formats

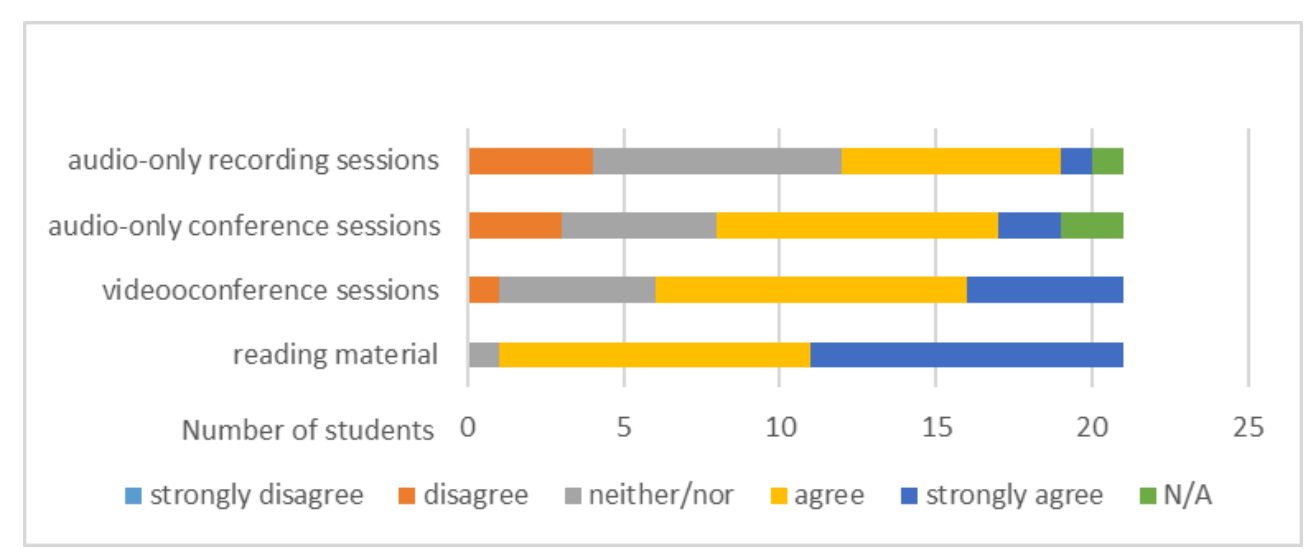

As for the online experience of the TOEIC preparation module, the majority of participants appear to have been able to navigate on the course site, find and download the course material, such as audio tracks and listening comprehension exercises, without difficulty. The question-and-answer forum was also found to be useful by the majority of the participants (90\%) in the science group, where it was tested. However, only $39 \%$ of participants consider that the content explored in class was "exactly the same" as what is to be expected in a traditional face-to-face classroom. Therefore, in spite of the positive feedback, students do not yet consider online classes an authentic class experience: as a result, their implication and motivation may differ greatly when faced with the two competing modes of learning. In the future, it would be interesting to find ways of further reassuring students about the validity of online classes, in an attempt to reduce to a greater extent the somewhat adverse viewpoint.

\subsection{Self-regulation, class interaction and self-evaluation}

As the dynamics of online classroom management differs from its traditional counterpart, self-regulation of students becomes an important factor in shaping their own online experience. The survey results indicate that the majority of participants did not follow instructions in executing coursework. Thirteen participants out of twentyone $(62 \%)$ claim to have listened to the audio tracks more than once while working on the listening comprehension exercises; twelve participants (57\%) responded that they 
did not always respect the time limit for the reading comprehension exercises; and eleven participants $(52 \%)$ responded that they did not time themselves when working on the reading comprehension exercises. While these issues may appear minor for traditional in-class activities in a second language classroom, they are disadvantageous for the present course as they suggest that participants are not actually preparing themselves optimally. It is worth noting that the TOEIC test operates in a strict timecontrolled setting where time management is of upmost importance and test-takers are not afforded the opportunity, for instance, of listening to an audio track twice.

Some of the survey questions sought to enquire into the expectations of students in terms of interactions that occur within a second language classroom. Expectedly, participants seem to attach great importance to the role of the teacher (see Figure 3). Moreover, when asked to rate their experience of class interactions, participants show a relatively high level of satisfaction. Teacher-to-class interaction, which they deem the most important in a classroom, received the most positive feedback: $43 \%$ of the participants responded that they were "very satisfied" and $24 \%$ were "satisfied". The interactions to which the participants gave less importance were evaluated as relatively less satisfying or neutral. This indicates that the expectations of the students regarding class interaction were in line with what the instructors sought to provide as a priority in the TOEIC preparation module.

Figure 3: Rating types of classroom interactions

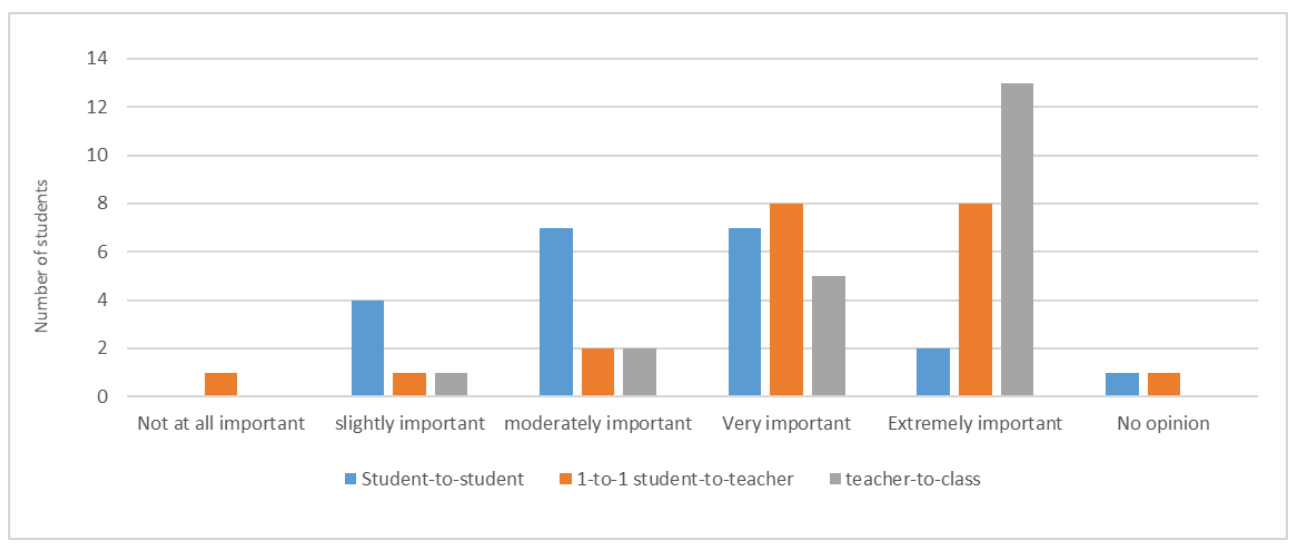

Lastly, the question which required participants to evaluate their overall experience of online learning during the TOEIC module garnered the most varied responses: while four participants were "very satisfied" and eight "satisfied", seven felt "neutral" and two were "dissatisfied". The participants were also asked to rate different aspects of online learning that they experienced through the TOEIC preparation module. Most expressed a high level of satisfaction in the progress that they made in working autonomously online, and the vast majority $(90 \%)$ responded that they found the module helpful in preparing them for the TOEIC test.

Overall, the results appear consistent throughout the survey. On the one hand, the questions concerning the content of the course and class interaction consistently generated positive feedback. On the other hand, the participants appear to have mixed feelings regarding the online learning experience: as mentioned earlier, some of them were faced with personal constraints linked to equipment and work environment; and the majority of the participants were neutral in their response when describing their experience of exploring and utilizing the course site. The fact that the instructions for 
listening and reading exercises were not, for the most part, respected, could have furthermore contributed to the sentiment that the content explored in class was different from what one would expect in a traditional face-to-face class.

\section{Assessment of learning outcomes and programme: instructors' outlook}

Let us now examine the questionnaire results relating to the teaching strategies that were put in place, rather than relating to the course content and format along with the impact the national lockdown had on the current teaching module.

\subsection{Impact of teaching strategies on students}

One of the rationales behind the stark differences in teaching strategies, as mentioned earlier, was to assess their impact on the delivery and reception of the TOEIC module and ultimately on the students. While the two teaching groups seem to display similar tendencies, perspective and satisfaction, a closer look highlights four noteworthy details: the humanities group had a slightly more positive experience during the online module and also had a greater appreciation of their teacher-to-class (see Figure 4) and one-to-one teacher-to-student interactions. On the other hand, the science group has a slightly greater appreciation of the course content and their estimated level of preparedness for the TOEIC test (see Figure 5).

Figure 4: Rating teacher-to-class interaction

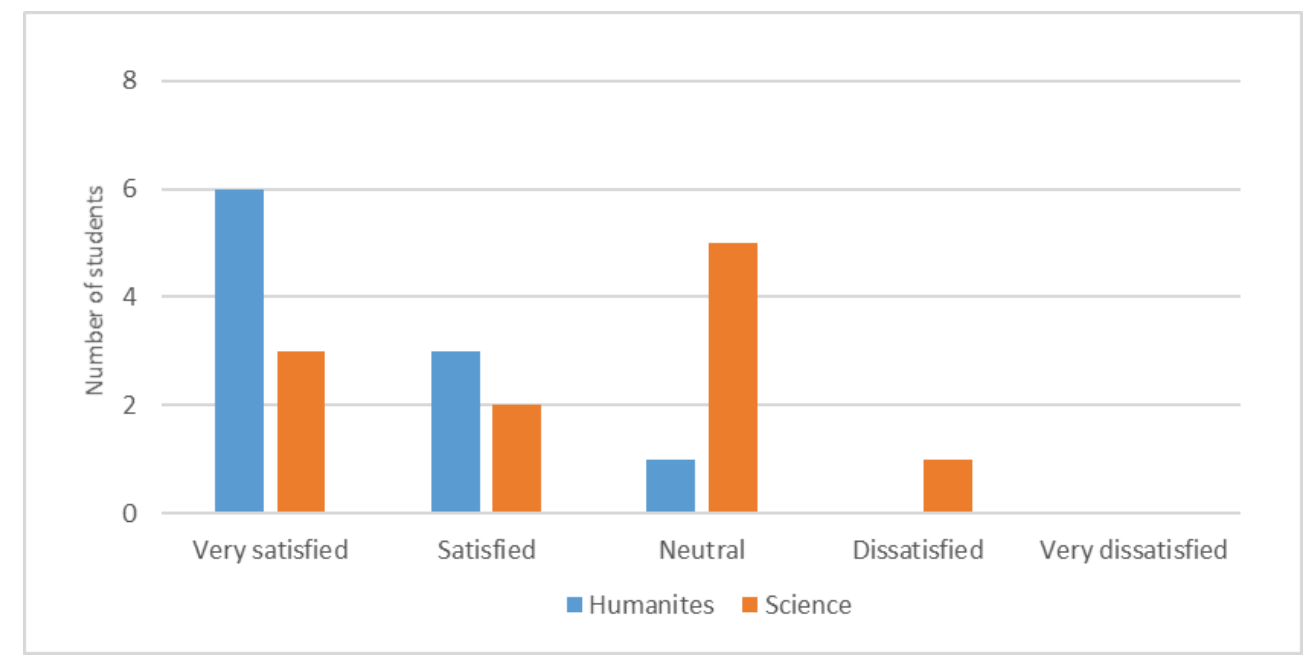


Figure 5: Rating the level of TOEIC preparedness

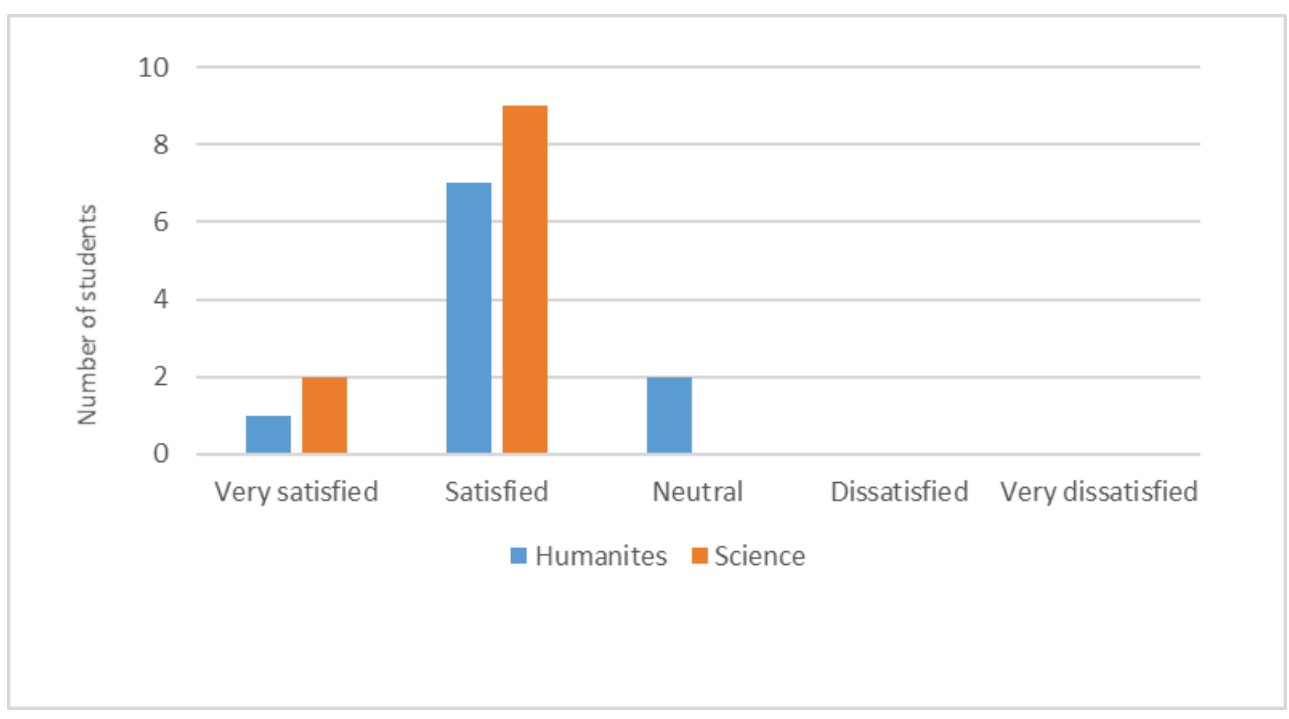

While the small class size may have a limiting effect on the comparison, the highlighted impact seems directly linked to the format and teaching approaches adopted in each group. As a reminder, for each 2-hour session the humanities group (cf. problemsolving approach) had an hour of videoconferencing followed by coursework, whereas the science group (cf. knowledge-based approach) had 30-minutes of audio conference followed by coursework and drills. In hindsight, creating an automated classroom environment, however detailed it may appear where lessons and activities are prerecorded and pre-programmed with minimal interactivity, may not be the most conducive learning environment for language learners. Alternatively, while an online course should be made as interactive as possible, it is important to not sacrifice traditionally deemed important content - whatever the reason or however technical the learning platform may be.

\subsection{Impact of national lockdown on the course}

40 The national lockdown situation did not affect the course objectives nor design but impacted how it was delivered and evaluated. As a traditionally blended-learning course, with the online component being considered secondary or complementary to that proposed in class, the national lockdown situation obliged instructors to replace virtually all material as explained in section 2.3 . This last-minute change was a source of stress for instructors, as the nature of the TOEIC certificate requires any reasonable preparation course to rely primarily on approved or official ETS material. Failure to do so may result in poor preparation and, possibly, lower TOEIC scores.

41 Equally noteworthy is the issue of time management. The post-course questionnaire revealed that students had not been meticulous in their time management, which leads us to believe that the diagnostic test, mock exams and other drills may not reflect the participants' true TOEIC score. A possible disingenuous consequence of the inflated score may cause students to adopt further a laid-back attitude, while failing to respect official exam conditions. As a result, there may be less effort put into subsequent assignments or drills, or the inflated score may create a false sense of security. For instance, the current version of the TOEIC listening comprehension section proposes 
100 items that must be answered in 45 minutes. Therefore, while the habit of rewinding and listening to an audio track multiple times to ensure comprehension may appear to be a positive strategy in an ordinary language learning environment, it becomes a penalising one under exam conditions.

What's more, the actual external TOEIC test for our students was scheduled in the month of July: i.e. directly at the end of the preparation module. Given that the training assignments and drills were specific to each group, the official test results were to be used as an additional tool in evaluating the two teaching strategies in place. While the questionnaire is an important part of the assessment, the external results were to provide an objective means of comparison. This option is no longer viable because the next TOEIC session is still not programmed, which means that there would be a considerable lapse of at least three months between the preparation course and the actual test. Needless to say that those results can no longer be considered decisive in the overall assessment of the learning outcomes and the programme. The programme assessment is now based solely on the feedback of instructors and students, which is no less deserving but simply an unexpected change.

To counter this issue in the future, it would be interesting to create an in-house shared final task to compare further the effects of the two teaching strategies. This shared task between groups could be used simultaneously to evaluate the level of TOEIC preparedness as well as the level of acquired ESP awareness (see section 2), which is currently not assessed outside of the distinct ESP modules of the DULASC programme.

\section{Conclusion}

The national lockdown situation did not affect the course objectives nor design but impacted how it was delivered and evaluated: notably, shifting from blended learning to an e-learning module and from strict course evaluation to flexible self-managed assessment with far-reaching implications. Based on current feedback from students and instructors, the teaching approaches under appraisal show minor differences. It is assumed, however, that the postponed external assessment would have been a decisive element in further distinguishing the two competing approaches.

Despite the significant changes that students experienced while adapting to online learning, as well as to the different teaching approaches that were put in place in each group, the student feedback demonstrates an overall satisfaction in the TOEIC preparation module. Moreover, in spite of the fact that some elements of face-to-face learning favoured by students can be replicated to a certain extent using online platforms, it is important to acknowledge that online and face-to-face classroom settings are and will remain different in a number of defining aspects. Trying to replicate all the elements of face-to-face classes in an online course would therefore prove difficult-even impossible-and is likely to leave students feeling that online courses are lacking in comparison. Therefore, it may be worthwhile to enquire into advantages that online learning can provide over face-to-face configurations, and use these advantages to further enrich the online student learning experience. 


\section{BIBLIOGRAPHY}

ARISPE, Kelly \& Robert J. BLAKE. 2012. "Individual factors and successful learning in a hybrid course”. System 40/4 449-465. https://doi.org/10.1016/j.system.2012.10.013

GARRISON, D. Randy \& Norman D. VAUGHAN. 2008. Blended Learning in Higher Education. Framework, Principles, and Guidelines. San Francisco: Jossey-Bass.

HEGARTY, Seamus. 2000. Teaching as a Knowledge-Based Activity. Oxford Review of Education, 26(3/4), 451-465.

HUHTA, Marjatta., Karin vogT, Esko JoHnSON \& Heikki TULKKI. 2013. Needs Analysis for Language Course Design: A Holistic Approach to ESP. Cambridge: Cambridge University Press.

HUVER, Emmanuelle. 2012. "Evaluation, changement, représentations - Vers une interrogation de quelques allants de soi en didactique des langues”. Cahiers de l'ASDIFLE 23 13-24.

JALENIAUSKIENE, Evelina. 2016. Revitalizing foreign language learning in higher education using a PBL curriculum. Procedia - Social and Behavioral Sciences, 232, 265-275.

LAMY, Marie-Noëlle \& Régine HAMPEL. 2007. Online Communication in Language Learning and Teaching. Basingstoke, Hampshire : Palgrave Macmillan

MÉMET, Monique. 2001. "Bref historique de l'enseignement et de la recherche en anglais de spécialité en France: de l'anglais pour non-spécialistes à l'anglistique du secteur LANSAD”. In MÉMET, Monique \& Michel PETIT (éds.) L'anglais de spécialité en France: Mélanges en l'honneur de Michel Perrin. Bordeaux: GERAS Éditeur, 309-319.

NICOLSON, Margaret, Linda MURPHY \& Margaret SOUTHGATE. 2011. Language Teaching in Blended Contexts. Edinburgh: Dunedin.

NISSEN, Elke. 2014. "Les spécificités des formations hybrides en langues”. Alsic. 17. https://doi.org/ $10.4000 /$ alsic. 2773

NARCY-COMBES, Marie-Françoise, Jean-Paul NARCY-COMBES, Julie MCALLISTER, Malory LECLÈRE \& Grégory MIRAS. 2019. Language Learning and Teaching in a Multilingual World. Bristol: Multilingual Matters.

PERAYA, Daniel, Bernadette CHARLIER \& Nathalie DESCHRYVER. 2014. "Une première approche de l'hybridation". Education et Formation 301 15-34.

SHIELD, Lesley. 2000. Overcoming Isolation: The loneliness of the Long Distance Learner. In European Association of Distance Teaching Universities, Wiring the Ivory Tower. Linking Universities Across Europe: EADTU Millennium Conference, Paris. Paris: EADTU, 297-302.

SWALES, John. 2016. Reflections on the Concept of Discourse Community. ASp, 69, 7-19.

\section{APPENDIXES}

\section{Questionnaire}

This short questionnaire is part of a small-scale project, which aims to obtain students' perspective on this year's TOEIC preparation course. The answers will help to identify the features that should be repeated, reinforced or discarded in the future. Your 
contribution is therefore highly valued. The questionnaire requires approximately 5 minutes.

NB: *N/A means not applicable and can be chosen if an option does not concern your DULASC group

1) Gender \& DULASC group

2) Please selection your highest level of education

> Bachelor's degree | Master's degree | Doctoral degree | Other

3) During this TOEIC preparation course, did you have unlimited access to a personal computer? > Yes | No

4)a Did your internet speed/bandwidth interfere in any way with the online course experience? > Yes $\mid$ No

4)b If you answered yes above (4a), please specify

> Slow downloads | Poor video or audio quality in conference sessions | Other

5) Were you always able to work efficiently, in a calm environment, during the weekly sessions? > Yes $\mid$ No

6) Did you have any previous experience with online classes (i.e. e-learning/distance learning) before this TOEIC module? > Yes | No

7) Did you have any previous experience with Moodle or any similar online learning platforms? > Yes $\mid$ No

8) To what degree do you agree with the following statements?

\begin{tabular}{|l|l|l|l|l|l|l|}
\hline & $\begin{array}{l}\text { Strongly } \\
\text { disagree }\end{array}$ & Disagree & $\begin{array}{l}\text { Neither } \\
\text { agree nor } \\
\text { disagree }\end{array}$ & Agree & $\begin{array}{l}\text { Strongly } \\
\text { agree }\end{array}$ & $\begin{array}{l}\text { Not } \\
\text { applicable }\end{array}$ \\
\hline $\begin{array}{l}\text { The course outline and } \\
\text { objectives were clear }\end{array}$ & & & & & & \\
\hline $\begin{array}{l}\text { The overall organisation of the } \\
\text { course was satisfactory }\end{array}$ & & & & & & \\
\hline $\begin{array}{l}\text { The reading material (pdf, } \\
\text { powerpoints, images, etc] were } \\
\text { sufficient }\end{array}$ & & & & & & \\
\hline $\begin{array}{l}\text { The sessions with BOTH video } \\
\text { and/or audio conference [and } \\
\text { reading material] were } \\
\text { sufficient }\end{array}$ & & & & & & \\
\hline $\begin{array}{l}\text { The sessions with ONLY audio } \\
\text { conference [and reading } \\
\text { material] were sufficient }\end{array}$ & & & & & & \\
\hline
\end{tabular}




\begin{tabular}{|l|l|l|l|l|l|l|}
\hline $\begin{array}{l}\text { The sessions with ONLY audio } \\
\text { recordings [and reading } \\
\text { material] were sufficient }\end{array}$ & & & & & & \\
\hline $\begin{array}{l}\text { The question and answer (Q\&A) } \\
\text { forum (if provided) was useful }\end{array}$ & & & & & & \\
\hline $\begin{array}{l}\text { The content explored in class is } \\
\text { exactly the same as one would } \\
\text { expect in a traditional face-to- } \\
\text { face class. }\end{array}$ & & & & & & \\
\hline
\end{tabular}

9) The content of the Module 5 TOEIC Preparation was *

\begin{tabular}{|l|l|l|l|l|l|}
\hline & 1) Very poor & 2) Poor & 3) Fair & 4) Good & 5) Excellent \\
\hline Scale & & & & & \\
\hline
\end{tabular}

10) How would you evaluate the experience of downloading the audio tracks and finding the corresponding listening comprehension exercises? ${ }^{*}$

11) During the course...

\begin{tabular}{|l|l|l|}
\hline & Yes & No \\
\hline $\begin{array}{l}\text { For the listening comprehension exercises, did you listen to any of the audio tracks more } \\
\text { than one time before selecting an answer? }\end{array}$ & \\
\hline For the reading comprehension exercises, did you always respect the time limit? & & \\
\hline For the reading comprehension exercises, did you ever time yourself & & \\
\hline
\end{tabular}

12) How would you evaluate the importance of the following in a second language classroom? *

\begin{tabular}{|l|l|l|l|l|l|l|}
\hline & $\begin{array}{l}\text { Not at all } \\
\text { important }\end{array}$ & $\begin{array}{l}\text { Slightly } \\
\text { important }\end{array}$ & $\begin{array}{l}\text { Moderately } \\
\text { important }\end{array}$ & $\begin{array}{l}\text { Very } \\
\text { important }\end{array}$ & $\begin{array}{l}\text { Extremely } \\
\text { important }\end{array}$ & $\begin{array}{l}\text { No } \\
\text { opinion }\end{array}$ \\
\hline $\begin{array}{l}\text { Student-to- } \\
\text { student } \\
\text { interaction }\end{array}$ & & & & & & \\
\hline $\begin{array}{l}\text { One-to-one } \\
\text { student-to- } \\
\text { teacher } \\
\text { interaction }\end{array}$ & & & & & & \\
\hline
\end{tabular}




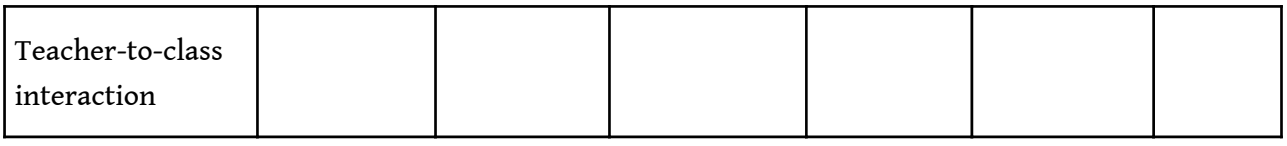

13) How would you rate your experience of the following in the TOEIC preparation module?

\begin{tabular}{|l|l|l|l|l|l|}
\hline & $\begin{array}{l}\text { Very } \\
\text { satisfied }\end{array}$ & Satisfied & Neutral & Dissatisfied & $\begin{array}{l}\text { Very } \\
\text { dissatisfied }\end{array}$ \\
\hline Student-to-student interaction & & & & & \\
\hline $\begin{array}{l}\text { One-to-one student-to-teacher } \\
\text { interaction }\end{array}$ & & & & & \\
\hline Teacher-to-class interaction & & & & & \\
\hline
\end{tabular}

14) Final overall impression: how would you evaluate the following?

\begin{tabular}{|l|l|l|l|l|l|}
\hline & $\begin{array}{l}\text { Very } \\
\text { satisfied }\end{array}$ & Satisfied & Neutral & Dissatisfied & $\begin{array}{l}\text { Very } \\
\text { dissatisfied }\end{array}$ \\
\hline $\begin{array}{l}\text { The progress that you have made in } \\
\text { working autonomously online }\end{array}$ & & & & & \\
\hline $\begin{array}{l}\text { Did this module help you feel better } \\
\text { prepared for the TOEIC test }\end{array}$ & & & & & \\
\hline $\begin{array}{l}\text { Your experience of online learning } \\
\text { during this module }\end{array}$ & & & & & \\
\hline
\end{tabular}

15) Any final thoughts or comments about your experience with online learning?

\section{NOTES}

1. Educational Testing Service (ETS) is a non-profit educational testing assessment organization whose products include TOEFL and TOEIC tests.

2. LANgues pour Spécialistes d'Autres Disciplines (LANSAD) is a term coined by Michel Perrin (Mémet 2001) and refers to students enrolled in second language courses as an elective, as opposed to majoring in the second language. 


\section{INDEX}

Mots-clés: anglais de spécialité, conception de cours enseignement hybride, enseignement à distance, stratégies d'enseignement, TOEIC

Keywords: blended learning, course design, e-learning, English for Specific Purposes, teaching strategies, TOEIC

\section{AUTHORS}

\section{CLIVE HAMILTON}

Clive Hamilton is Associate Professor of English Linguistics and Translation at Université de Paris. After teaching English for Academic Purposes for several years, he now teaches courses in English linguistics, phraseology, terminology and specialised translation. His principal research interest lies in the use of specialised corpora in a didactic perspective, including the analysis of French and English academic discourse and the analysis of learner corpora. clive.hamilton@uparis.fr

\section{LINDSEY PAEK}

Lindsey Paek teaches English for Specific Purposes at Université de Paris (former Université Paris-Diderot). She is also currently writing her Ph.D. dissertation within the Cultures et Littératures des Mondes Anglophones (CLIMAS) laboratory at Université Bordeaux Montaigne. Her Ph.D. focuses on ethnic identity negotiation of Korean immigrants in Toronto, Canada, and how they contribute to the nation-building of Canada as a multicultural nation.

lindseyjpaek@gmail.com 